\title{
ANTAGONISM BETWEEN SALTS AND ANESTHETICS \\ IV. INACTIVATION OF SALT SOLUTIONS AND HYPERTONIC SEA-WATER BY ANESTHETICS
}

RALPH S. LILLIE

From the Marine Biological Laboratory, Woods Hole, and the Physiological Laboratory, Clark University

The physiological antagonism about to be described forms a special instance of the class discussed in my three recent papers on the interference of anesthetics with the stimulating and toxic action of salt-solutions. ${ }^{1}$ In the second paper I described experiments showing that the cytolytic action of isotonic solutions of various neutral salts on the unfertilized eggs of sea-urchins and starfish was retarded or prevented in the presence of certain anesthetics. The eggs were thus enabled to withstand more prolonged exposures to the anesthetic-containing than to the pure solutions without losing their power of development. Substances of this class may thus exhibit a well-marked protective or anti-cytolytic action similar to that of calcium or magnesium chloride, although as a rule less pronounced.

I have also shown in former papers that the initiation of cleavage by pure isotonic solutions of sodium or potassium salts may be prevented by calcium or magnesium chloride. ${ }^{2}$ This effect is a typical instance of salt-antagonism. There is every indication that the pure or unbalanced salt-solution acts primarily on the plasma-membrane or surface-layer of the egg, causing among other effects a rapid and well-marked increase of permeability, with which is probably associated an electrical depolarization. ${ }^{3}$ The antagonistic salt counteracts this permeabilityincreasing action; hence it also prevents the cleavage-initiating

${ }^{1}$ Am. Jour. Physiol., 1912, vol. 29, p. 372; vol. 30, p. 1; 1913, vol. 31, p. 255.

${ }^{2}$ Am. Jour. Physiol., 1911, vol. 27, p. 289; Jour. Morph., 1911, vol, 22, p. 695.

${ }^{3}$ Cf. Am. Jour. Physiol., 1910, vol. 26, p. 106. 
action which is dependent upon the change of permeability. Since anesthetics, as well as calcium and magnesium, render the plasma-membrane more resistant to the permeability-increasing action of salt-solutions, ${ }^{4}$ they ought-if the above point of view is correct-also to prevent the cleavage-initiating action of these solutions. It was with this expectation that the following experiments were begun.

A well-marked antagonism of this kind was readily demonstrated in Arbacia eggs, although again as with the above anticytolytic action the anesthetics were found to be less effective than calcium or magnesium. The same anesthetics were used as in the preceding experiments with fertilized eggs, ${ }^{5}$ in the concentrations there found just sufficient to prevent cell-division. The addition of anesthetics to the pure salt-solutions used (0.55 $\mathrm{m}$ KCNS and $\mathrm{NaI}$ ) was found in many instances greatly to decrease the cleavage-initiating action of these solutions. Many of the eggs after exposure to the anesthetic-containing saltsolutions for five minutes remained to all appearance unchanged, while those treated similarly with the same salt-solution, free from anesthetic, all formed fertilization-membranes and underwent change of form or cleavage. ${ }^{6}$

The different anesthetics, however, were found to vary greatly in their ability thus to prevent the characteristic action of the salt-solution without injury to the eggs. Chloral hydrate and the urethanes proved much less effective in this respect than the alcohols, although, as shown in my paper on the influence of anesthetics on cleavage, ${ }^{7}$ they are more favorable for anesthetizing the cleavage-process. The ability to counteract the saltaction thus need not run parallel with the power of suppressing cleavage. The case of potassium cyanide affords a further illustration of this difference in the influence of the same compound on these two processes. Cyanide does not appreciably interfere

4 Loc. cit., 1912.

${ }^{5}$ Cf. Jour. Biol. Chem., 1914, vol. 17, p. 121.

- After-treatment with hypertonic sea-water is, of course, necessary to make such eggs develop to advanced stages.

7 Loc. cit., 1914. 
with the initiation of cleavage by the above salts, in spite of its powerful action in suppressing cleavage-a fact, it may incidentally be pointed out, indicating once more that this agent differs essentially in its mode of action from the anesthetics. That the normal course of the cleavage process is completely inhibited by anestheties which only slightly counteract the salt-action probably indicates that a greater degree of resistance must be imparted to the plasma-membrane to prevent the action of the salt than to suppress cleavage; chloral hydrate and urethane are apparently less able than the alcohols to impart to the membranes the necessary stability or degree of resistance. The case of cyanide is different. Cyanide acts by directly inhibiting oxidations, and arrests cleavage through a quite different means from that exercised by the anesthetics, which appear to act primarily by altering the condition of the plasma-membrane and thus incapacitating this structure for the exercise of its normal activities.

Precisely how this effect is produced is undecided and requires further investigation; in some way-as I have shown in the experiments cited above-the presence of definite quantities of many lipoid-solvent anesthetics imparts an increased stability to the colloidal surface-films of cells and to other surface-structures such as cilia. Some change in the physico-chemical relations existing between the lipoid and protein components of the colloidal complex seems thus indicated. It has long been known that one colloid may exert a stabilizing influence upon another when the two are present together in solution. The lipoids and proteins of the plasma-membrane are possibly interrelated in some such manner; ${ }^{8}$ if so, altering the condition of the lipoids will naturally affect the stability of the colloidal system, and under appropriate conditions (of temperature, concentration, etc.) will increase it. When this occurs, activities dependent on alterations of the plasma-membrane-especially the effects normally following changes of electrical polarization-are inhibited. The resulting state of temporary inactivity or irresponsiveness-what we call anesthesia or narcosis in irritable

B The observations of Lepeschkin are of much interest in this connection; cf. Kolloid-Zeitschrift, 1913, Bd. 13, p. 181. 
tissues-appears to be the expression of this change in the physicochemical properties of the plasma-membranes.

It was interesting to find that although anesthetics may thus inhibit the cleavage-initiating action of neutral salts, they have no appreciable influence on the similar action of the lipoidsolvent fatty acids. This observation has an intimate bearing on the general question of the mechanism of anesthetic action, as well as on that of the nature of the process underlying the initiation of cleavage. The fatty acid evidently acts by influencing the condition of the lipoids, and this effect is not prevented by anesthetics; the salt-action, on the other hand, which presumably affects all of the colloids and particularly the proteins of the membrane, is interfered with by these substances. It would thus seem that the salt and the fatty acid may produce the same effect by an action on different constituents of the plasma-membrane. I shall discuss the possible implications of this difference in the relation of anesthetics to these two cleavage-initiating agencies in the concluding section of this paper.

\section{EXPERIMENTAL}

Influence of anesthetics on the cleavage-initiating action of neutral salts (KCNS, NaI)

The procedure in these experiments was essentially as follows. The unfertilized Arbacia eggs were exposed for a brief period (four or five minutes) to the pure isotonic solution of the salt used ( $0.55 \mathrm{~m} \mathrm{KCNS}$ or $\mathrm{NaI}$ ), containing the anesthetic in known concentration; they were then returned to sea-water. Eggs treated in this manner with the pure salt-solution, free from anesthetic, form fertilization-membranes and cleave as described in my former paper; and if treated further with hypertonic seawater a large proportion form blastulae. But of those eggs treated with the salt-solution containing a favorable anesthetic in the appropriate concentration a considerable and sometimes large proportion, varying with the anesthetic and time of exposure, remain to all appearance quite unaffected, showing no 
sign of development or other change. If such eggs are fertilized, even after lying in sea-water for many hours (e.g., overnight) they develop into free-swimming larvae, showing that the eggs have not been essentially injured, but that the salt-solution has simply been prevented by the anesthetic from exerting its usual action. The degree of this preventive or antagonistic influence was estimated by comparing the respective proportions of eggs remaining thus unaltered after exposure to the pure and to the anesthetic-containing salt-solutions. In the majority of experiments eggs were also exposed-about fifteen minutes after the treatment with salt-solution - to hypertonic sea-water (100 volumes sea-water plus 16 volumes $2.5 \mathrm{~m} \mathrm{NaCl}$ ) for twenty minutes. The effect of the addition of anesthetics on the action of the hypertonic sea-water was also investigated. In most of the experiments the eggs were anesthetized in sea-water previously to being exposed to the anesthetic-containing salt-solution, i.e., were placed for about half an hour in sea-water containing the same anesthetic in the same concentration as in the salt-solution. The antagonistic influence of the anesthetic is found to be more pronounced after this preliminary anesthetization than when the eggs are transferred directly from normal sea-water to the anesthetic-containing salt-solution.

The details of the manipulation were kept as constant as possible. Equal quantities of eggs from the same lot were used in the different experiments of any series. The anesthetic-containing solutions were prepared shortly before using and kept in corked flasks. The brief exposure to the salt-solution was made in finger-bowls; the pure or anesthetic-containing sea-water was removed as far as possible and to the mass of eggs remaining (usually 2 to $3 \mathrm{cc}$.) a relatively large volume (usually $50 \mathrm{cc}$.) of the corresponding salt-solution was rapidly added; at the end of the four or five minutes of exposure a large volume ( $c a .300 \mathrm{cc}$.) of sea-water was added and this was changed as soon as the eggs had settled, and again one or more times later. The sea-water in which the eggs were left after the final treatment was always changed several times to remove the last traces of anesthetic. 


\section{Experiments with potassium thiocyanate}

Table 1 summarizes the results of two typical series of experiments. These illustrate in a typical manner the characteristic effects of magnesium and calcium in preventing the cleavageinitiating action of the alkali salt; the four alcohols also show a well-marked though less pronounced antagonistic action. The superiority of amyl alcohol and the relative ineffectiveness of ethyl urethane are also typical.

It will be noted that the degree of antagonism is decidedly greater in the case of those eggs (Series B) that were anesthetized previously to the treatment with the salt-solutions. This effect had been foreseen; presumably the preliminary anesthetization alters the plasma-membranes of these eggs, which are thus already in a relatively resistant condition when brought into the salt-solutions; hence the action of the latter on these eggs is more gradual than on eggs transferred to the solutions directly from normal sea-water. In the latter case it is to be assumed that the salt begins to exert its action before the anesthetic has had time to produce its full effect. There is a similar difference in the action of anesthetic-containing sodium chloride solutions on normal and on anesthetized Arenicola larvae. ${ }^{9}$ Several other similar experiments gave the same general result.

The further fact appears clearly from these experiments that the anesthetics are less efficient than calcium and magnesium in counteracting the action of the alkali salt. A considerable and variable proptortion of the anesthetic-treated eggs form fertilization-membranes and cleave, and later break down like eggs treated with the pure anesthetic-free salt-solution. The proportion of protected and intact eggs may, however, reach 80 or 90 per cent with a favorable anesthetic like amyl alcohol; such eggs appear quite normal and remain without change for many hours; if fertilized they develop into swimming larvae.

The physiological condition of these eggs is, however, not the same as that of normal eggs, but has been altered, apparently in the same general direction as in those eggs which form definite

○ Cf. Am. Jour. Physiol., 1912, vol. 29, p. 384. 
fertilization-membranes and begin to cleave. This is true also, though to a less degree, of the eggs treated with the calciumor magnesium-containing solutions. The effects of after-treatment with hypertonic sea-water show the difference between such eggs and normal unfertilized eggs. Hypertonic sea-water acting on normal eggs for this length of time has no apparent effect, causing neither membrane-formation nor cleavage. Its action on eggs previously treated with anesthetic-containing saltsolutions is, however, definite and well-marked. Even those eggs which, if left alone, show no signs of membrane-formation or other change, begin development, and a considerable proportion-though smaller than in the case of eggs with definite fertilization-membranes-reach the blastula stage. Many, of course, die before reaching this stage. Both the above series and that of table 2 afford numerous instances of this kind. It is clear that some physiological modification has been produced in the eggs, of the same nature as that which normally leads to membrane-formation, but insufficient by itself to produce this effect. The eggs are, however, brought into a condition in which they respond more readily to the action of the hypertonic seawater. The antagonistic effect of the anesthetic is thus only partial; although no membranes are formed and there is no external sign of change, the eggs are rendered more responsiveor sensitized-to the subsequent action of the hypertonic seawater. Examination of the above and succeeding tables will show that the proportion of eggs remaining unaltered after the treatment with hypertonic sea-water is always small. A certain proportion, however, do remain thus unaltered, apparently those in which the protective action of the anesthetic has been most complete. Such variability is always observed, though its precise basis cannot be defined as yet. Similar conditions are seen in the eggs treated with $0.55 \mathrm{~m} \mathrm{KCNS}$ containing calcium or magnesium; these cations are decidedly more effective than the anesthetics, as shown above, and of the two magnesium has the greater action; always the great majority ( $>90$ per cent) of eggs treated with these solutions remain to all appearance quite unchanged, and if fertilized the next day develop normally. 


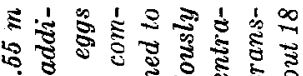

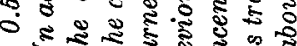
돈

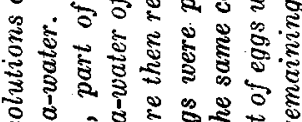

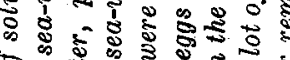
․ำ จิ

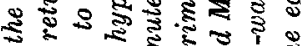

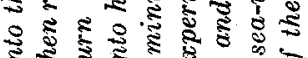

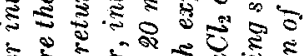
ํํำ ํํำ की ํํำ

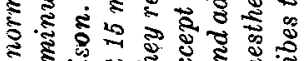

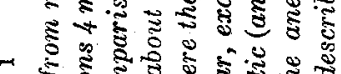

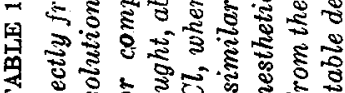

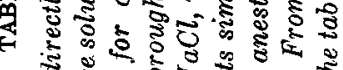
5. ำำ

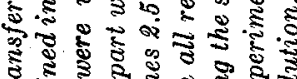
5.

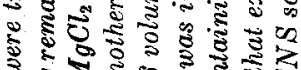

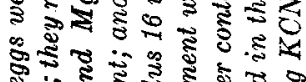

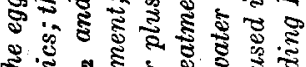

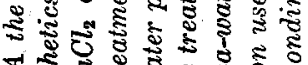

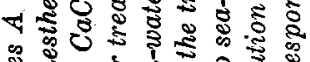

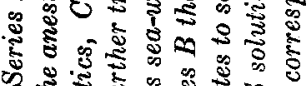
के

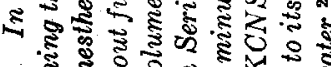

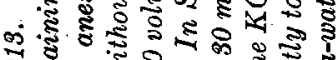

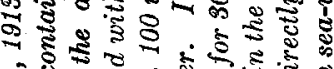

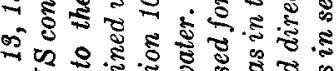

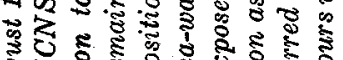

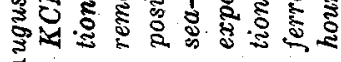

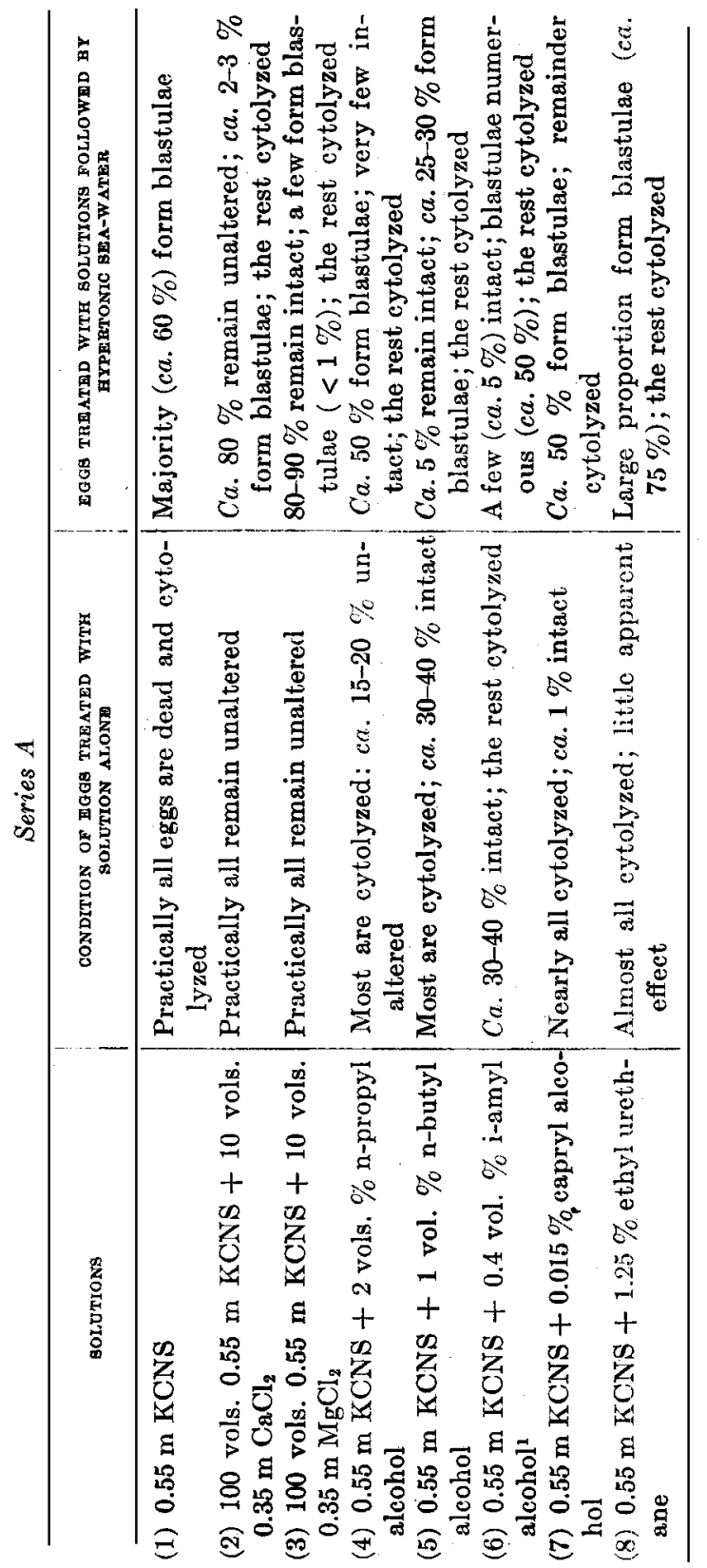




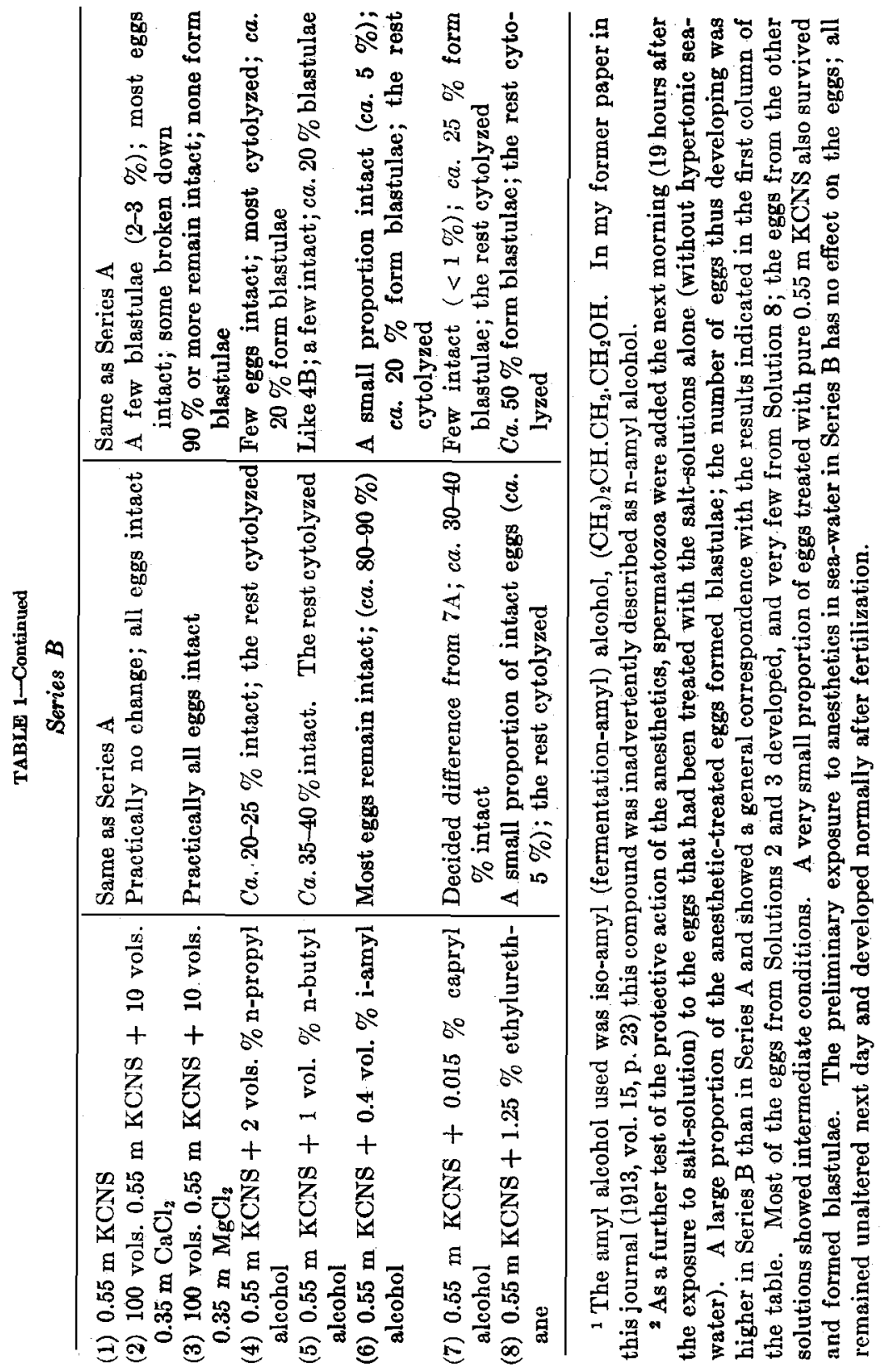


Nevertheless, the after-treatment with hypertonic sea-water initiates development in a certain small proportion of these eggs, some of which form blastulae, though most stop short of this stage and undergo cytolysis. It is clear from the altered character of the response to hypertonic sea-water that some persistent modification has been produced by the previous treatment with salt-solution. What the nature of this modification is can only be surmised at present. The most probable general hypothesis seems to be that the plasma-membrane has been altered in some definite way-possibly rendered more permeable or more susceptible to alterations of permeability under changed external conditions. A changed state of electrical polarization would presumably accompany such a modified condition. On this view the increased responsiveness to hypertonic sea-water is analogous to the increased responsiveness of frogs' voluntary muscle which has been sensitized by brief exposure to isotonic solutions of (e.g.) sodium citrate or other sodium salt." form of sensitization is almost undoubtedly dependent on a surface-alteration, since it is produced within a few seconds by salts. which either do not penetrate the normal plasma-membrane or do so with extreme slowness. ${ }^{11}$

The degree of protection afforded by the above alcohols may be decidedly greater than that shown in the above series. The following experiments (table 2) are especially favorable in this respect. These experiments also bring out clearly the effectiveness of anesthetics in inhibiting the characteristic action of hypertonic sea-water. Ethyl alcohol and phenyl urethane were used in addition to the anesthetics of table 1.

It will be seen from an examination of table 2 that the protective action of the alcohols is well-marked, while that of the urethanes, especially phenyl urethane, is comparatively slight. Amyl alcohol is distinctly superior to the others. These results are typical, as an examination of table 5 will show. A small proportion of the protected eggs remain unaffected by the after-

${ }^{10}$ Cf. J. Loeb, Am. Jour. Physiol., 1901, vol. 5, p. 362.

${ }^{11}$ Cf. my paper in the Proceedings of the Society for Experimental Biology and Medicine, 1910, vol. 7, p. 170. 


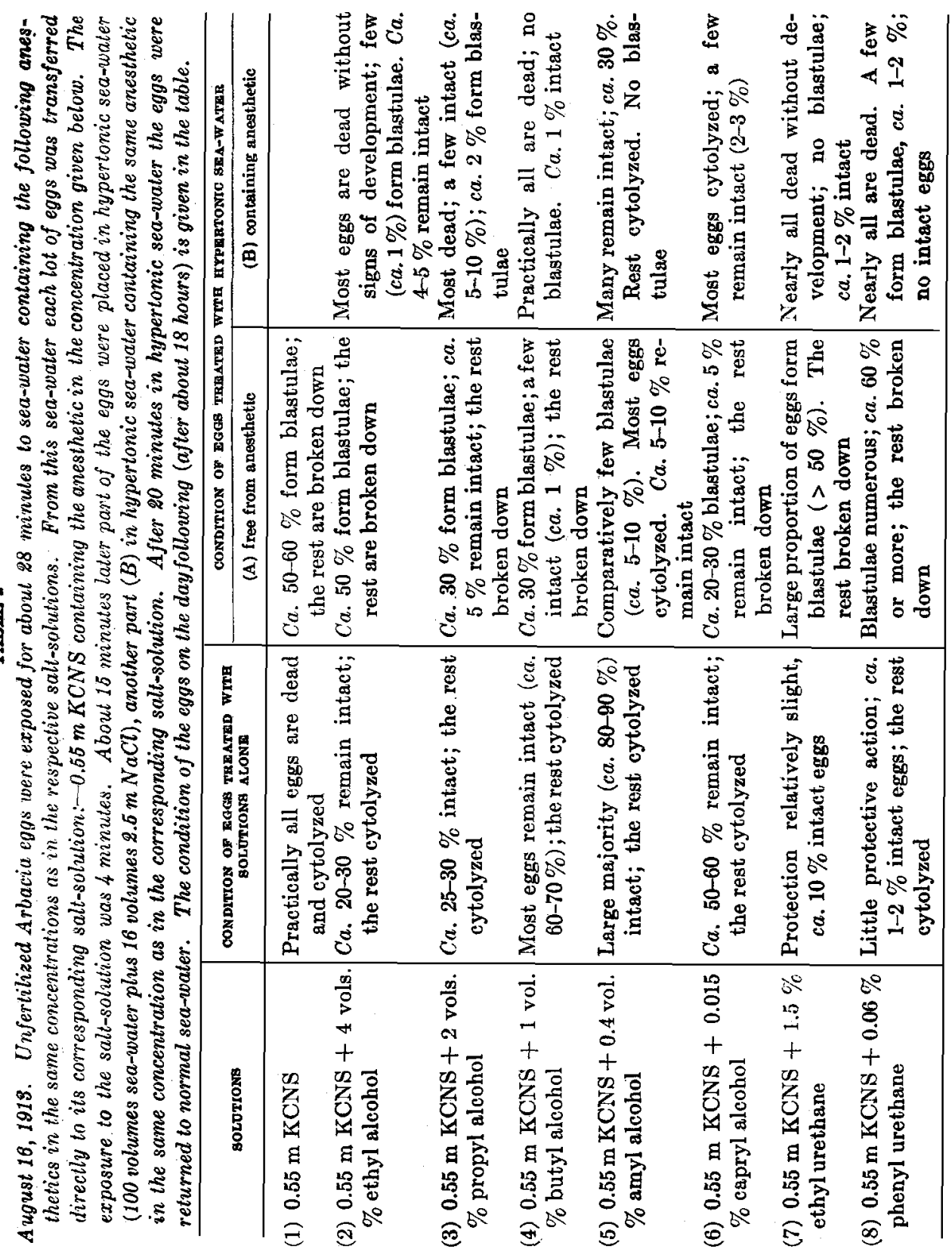


treatment with hypertonic sea-water and remain intact the next morning; but the majority either undergo cytolysis or develop to a blastula stage. The proportion of eggs forming blastulae is in general smaller the greater the protective action, indicating that when the membrane-forming action of the salt is prevented the eggs respond less readily to the hypertonic seawater; some entirely fail to respond.

It will be noted also that the presence of the anesthetic in the hypertonic sea-water greatly diminishes or entirely annuls the effectiveness of the after-treatment. Such hypertonic seawater is not, however, entirely indifferent in its action, as is shown by the fact that relatively few eggs so treated remain intact; most undergo cytolysis and a few may develop. The same result appeared in six other series of experiments with hypertonic sea-water containing anesthetics. The favorable effect of the treatment is, however, almost entirely prevented by the presence of anesthetics in the protective or anesthetizing concentrations.

Removal of oxygen from hypertonic sea-water or the addition of cyanide also prevents its characteristic action, as Loeb found for Strongylocentrotus. ${ }^{12}$ Cyanide has the same effect with Arbacia eggs (cf. table 3). Loeb has interpreted these facts as indicating that some chemical process involving oxidations underlies the favorable action of the hypertonic sea-water. That this agent acts by modifying chemical processes in the egg is also indicated by the high temperature-coefficient of the times of exposure. ${ }^{13}$ The fact that anesthetics have the same effect on the action of hypertonic sea-water as suppression of oxidations seems highly significant. Evidently the hypertonic sea-water induces some process of an oxidative nature; this process is checked or prevented by anesthetics. Now the anesthetics appear to act by altering the state of the lipoid components of the plasma-membrane, thus rendering this structure more resistant to change than normally: it thus appears probable that the

12 J. Loeb, Biochemische Zeitschrift, 1906, Bd. 1, p. 183.

${ }^{18} \mathrm{~J}$. Loeb, loc. cit.; also University of California Publications, Physiology, 1906, vol. 3, p. 39 . 
hypertonic sea-water exerts its characteristic action primarily by changing the state of the plasma-membrane, and that the oxidative processes underlying the favorable effect of this aftertreatment are a function of certain membrane-processes. We have thus further though somewhat indirect evidence that the plasma-membrane is a controlling factor in the intracellular oxidations. ${ }^{14}$

Chloral hydrate has little effect in preventing the action of $0.55 \mathrm{~m} \mathrm{KCNS}$. In five experiments with this anesthetic, in concentrations of 0.2 per cent to 0.1 per cent, the highest proportion of eggs remaining unaltered next day was $c a .10$ per cent (table 5). Potassium cyanide showed no signs of protective action in any experiment. The series shown in table 3 illustrates the results obtained with these compounds.

It will be noted that although chloral hydrate and cyanide are almost without influence on the cleavage-initiating action of $0.55 \mathrm{~m}$ KCNS, both prevent entirely the favorable effects of aftertreatment with hypertonic sea-water. This action was highly striking in the above series, since in every experiment the great majority of eggs formed blastulae after treatment with the pure hypertonic sea-water.

\section{Experiments with sodium iodide}

In experiments with this salt all the above alcohols showed well-marked protective action. The series summarized in table 4 will illustrate. The eggs were exposed to the freshly prepared $0.55 \mathrm{~m} \mathrm{NaI}$ for four minutes; this is too brief an exposure to cause membrane-formation in all eggs, and about 20 per cent remained intact next morning; the proportion remaining intact was, however, much greater in the anesthetized lot, and fewer of these eggs formed blastulae.

A second similar series with five minutes' exposure to $0.55 \mathrm{~m}$ $\mathrm{NaI}$, and containing in addition to the above alcohols ethyl urethane and chloral hydrate, gave similar results, although the protective effect was on the whole less pronounced. Urethane

\footnotetext{
${ }^{14}$ For more direct evidence of a relation of membranes to oxidations, ef. my recent paper in the Journal of Biological Chemistry, 1913, vol. 15, p. 237.
} 


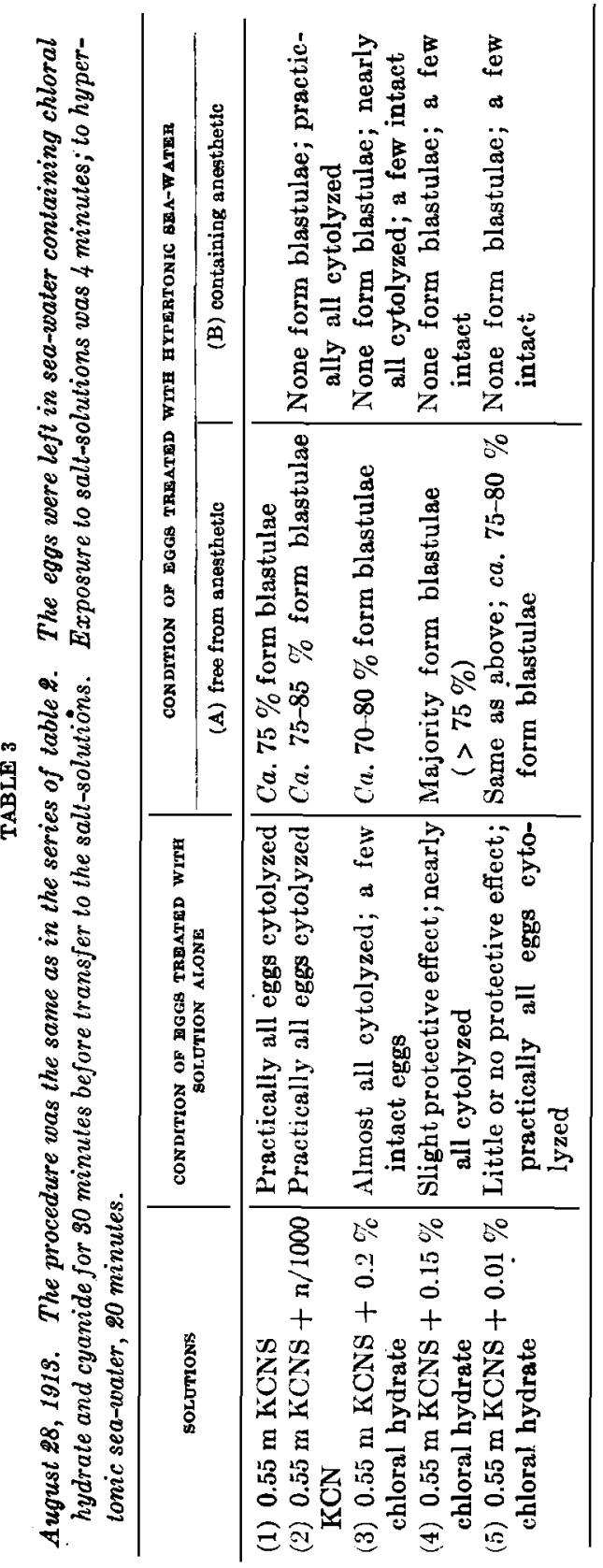




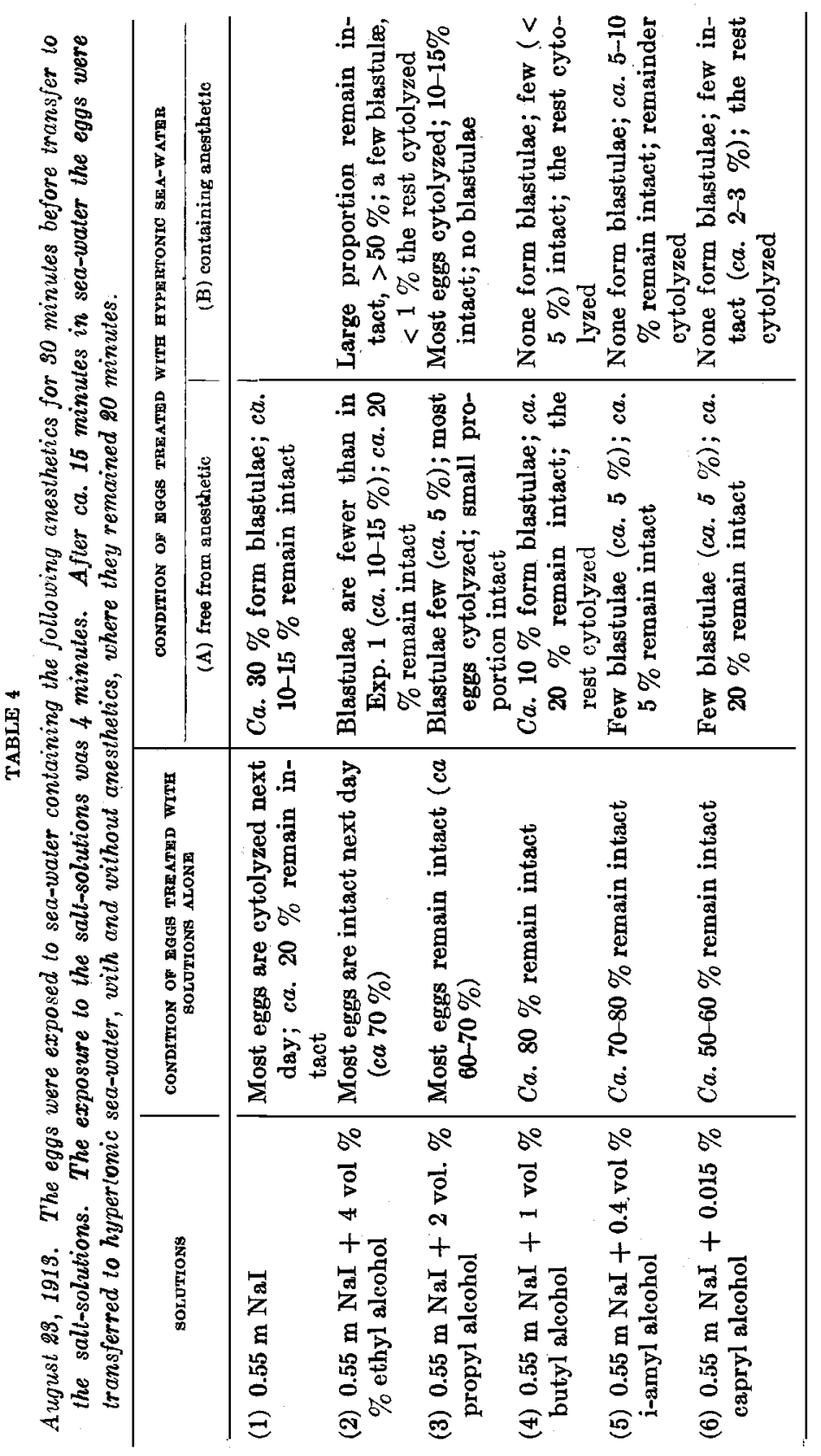


was only slightly effective, while chloral hydrate showed wellmarked action. In all cases the anesthetic prevented or greatly lessened the favorable effects of the after-treatment with hypertonic sea-water. The results with sodium iodide were thus in all respects similar to those with potassium thiocyanate.

In table 5 I have summarized the results of last summer's series of experiments with $0.55 \mathrm{~m}$ KCNS. The table includes the records of all experiments in which the eggs were exposed, previously to treatment with the anesthetic-containing salt-solutions to solutions of the same anesthetics in sea-water, in the manner already described. ${ }^{15}$ The figures give the estimated proportion of eggs remaining intact the next morning after the treatment with the anesthetic-containing salt-solution alone. In all cases the proportion of eggs surviving the treatment with the pure $0.55 \mathrm{~m}$ KCNS (without anesthetic) was small-never more than 1 or 2 per cent.

The concentrations of anesthetic used in these experiments are those which just suffice to prevent cleavage in most fertilized eggs, without causing immediate injury. ${ }^{16}$ The above solutions (with the exception of $2.4 \mathrm{v}$. per cent propyl alcohol and $1.2 \mathrm{v}$. per cent butyl alcohol, which are too strong) are thus, as regards their inhibiting effect on cleavage approximately equivalent. Nevertheless in their ability to prevent the cleavage-initiating action of salt solutions they show marked inequalities. The alcohols are greatly superior to chloral hydrate and the urethanes; amylalcohol is distinctly more effective than the others, while butyl alcohol appears somewhat more favorable than propyl or capryl, and ethyl is only moderately effective. This lack of parallelism between the anesthetic and the above protective actions may seem inconsistent with the general hypothesis advocated in this paper. But when the essential dissimilarity between the process of normal cleavage and the external action of a pure salt-solution is considered, the discrepancy ceases to be surprising. That

\footnotetext{
${ }^{16}$ With the exception of a few experiments in which the results of fertilization showed that the eggs were defective.

${ }^{1.6} \mathrm{Cf}$. my paper on the influence of anesthetics on cleavage cited above, pp. 128 seq.
} 


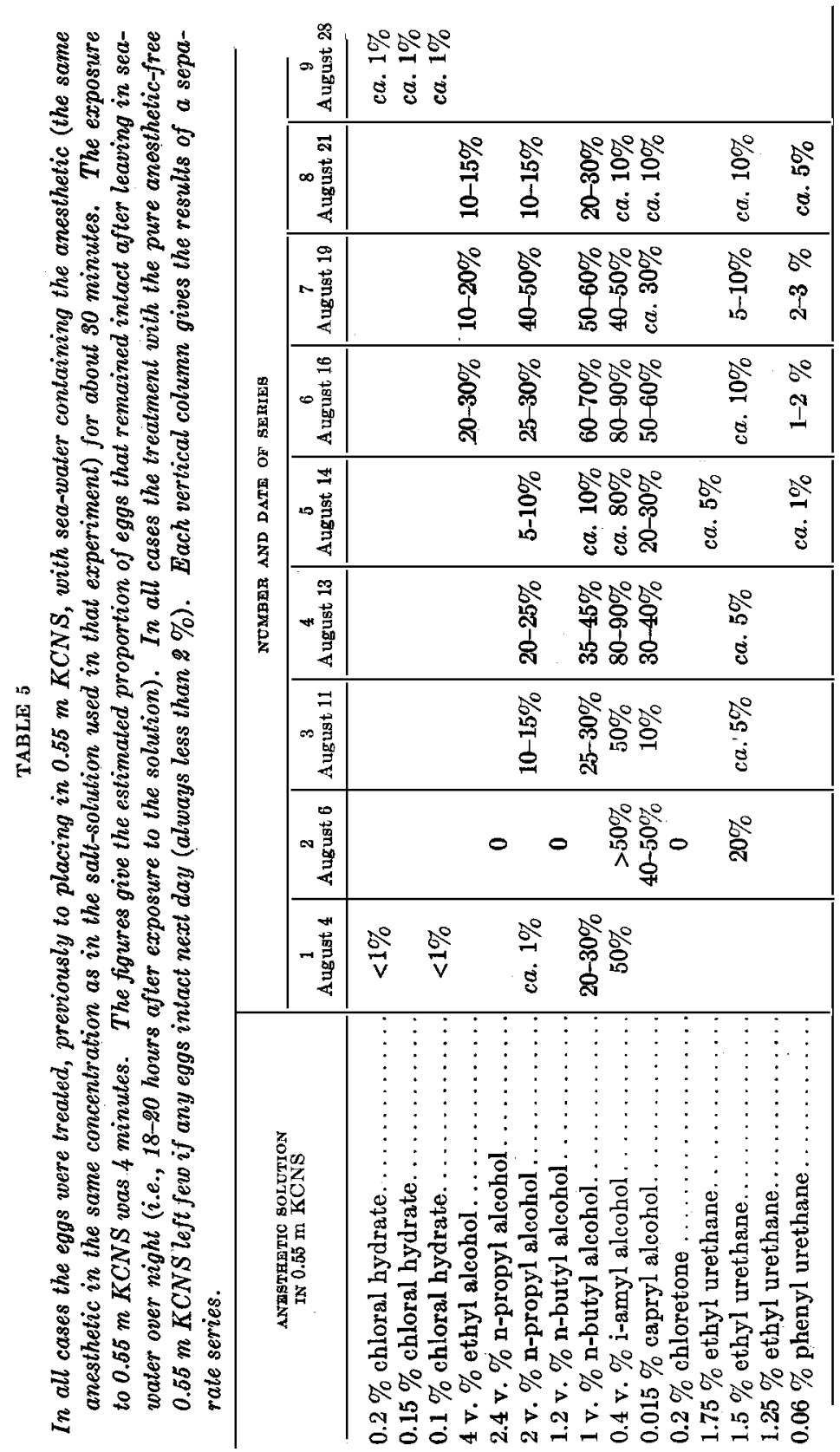


a given anesthetic may interfere with one set of processes and not with another has long been known. It would appear rather, as suggested above, that while chloral hydrate and the urethanes impart to the plasma-membranes a degree of resistance sufficient to prevent the normal changes of cleavage, this resistance is insufficient to prevent the relatively violent action of the pure salt-solution. The alcohols, for some reason as yet obscure, protect the egg more effectively against the latter action. They are, however, quite ineffective in preventing the cleavage-initiating and cytolytic action of fatty acids. The ability of an anesthetic to suppress or prevent a given process thus depends both on the nature of the anesthetic and of the process itself. The experiments with fatty acid about to be described will illustrate this.

The cleavage-initiating action of fatty acids in the presence of anesthetics

The above anesthetics entirely fail to interfere with the formation of fertilization-membranes or the initiation of cleavage by fatty acids. In a number of experiments, conducted similarly to those already described, in which the parthenogenetic agent was sea-water containing acetic or butyric acid ( 2 to 3 cc. $\frac{N}{10}$ fatty acid plus $50 \mathrm{cc}$. sea-water) the results were entirely negative. The addition of the anesthetic seems indeed to increase the injurious action of the acid. Chloral hydrate is equally ineffective. The urethanes were not tried. The following series with the alcohols will illustrate (Table 6).

From these experiments it is clear that the above anesthetics are completely unable to counteract the action of the fatty acid. Their antagonistic influence seems to be confined to the salts. Experiments with sea-water containing additional calcium and magnesium chloride (without altering the osmotic pressure) gave an analogous result. It was thought that possibly by increasing the proportion of these salts in the medium the eggs might be rendered more resistant to fatty acid. The following solutions were used: 100 volumes sea-water plus respectively 


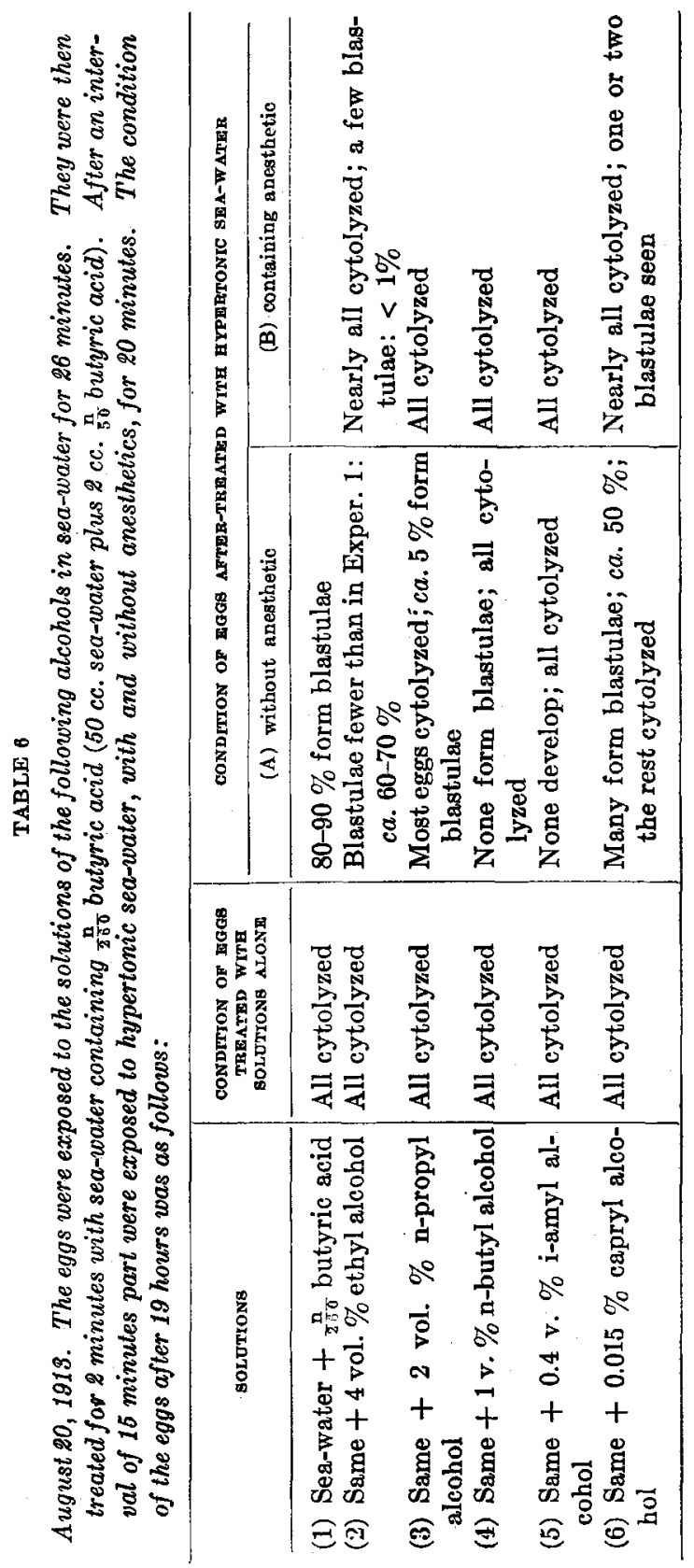


10,20 and 50 cc. $0.35 \mathrm{~m} \mathrm{MgCl}_{2}$, similar mixtures of $0.35 \mathrm{~m} \mathrm{CaCl}$ and sea-water, and mixtures containing both salts; 2 cc. $\frac{\mathrm{N}}{10}$ butyric acid was added to $50 \mathrm{cc}$. of each solution, and the action on unfertilized eggs was tested as above. The results again were entirely negative as regards protective action: in all cases two minutes' exposure to these solutions was followed by cytolysis. After-treatment with hypertonic sea-water proved ineffective in all cases, none of the eggs so treated forming blastulae (with the exception of a few from 100 volumes sea-water plus 10 volumes $0.35 \mathrm{~m} \mathrm{MgCl}_{2}$ ). The presence of an excess of calcium or magnesium in the sea-water thus prevents the eggs from developing favorably later, although it does not hinder the cytolytic action of the fatty acid. ${ }^{17}$

${ }^{17}$ Experiments, with unfertilized eggs conducted in the summer of 1911 on the antitoxic action of $\mathrm{CaCl}_{2}$ on isotonic $\mathrm{NaCl}$ solutions containing acetic acid gave entirely negative results. The following series will illustrate. Eggs were left for two hours in the solutions, then returned to normal sea-water and fertilized. The results were as follows (condition of the eggs next day):
(1) Pure $0.55 \mathrm{~m} \mathrm{NaCl}$
Solution
Result
(2) 95 vols. $0.55 \mathrm{~m} \mathrm{NaCl}+5$ vols. $-\frac{\mathrm{M}}{2} \mathrm{CaCl}_{2}$ ca. 40-50\% form blast ula
(3) $0.55 \mathrm{~m} \mathrm{NaCl}+\frac{\mathrm{N}}{200} \mathrm{CH}_{3} \mathrm{COOH}$. all form blastulae
(4) $0.55 \mathrm{~m} \mathrm{NaCl}+\frac{\mathrm{N}}{200} \mathrm{CH}_{3} \mathrm{COOH}+\frac{\mathrm{M}}{40} \mathrm{CaCl}_{2}$ all eggs dead
(5) $0.55 \mathrm{~m} \mathrm{NaCl}+\frac{\mathrm{N}}{400} \mathrm{CH}_{3} \mathrm{COOH}$. all dead
(6) $0.55 \mathrm{~m} \mathrm{NaCl}+\frac{\mathrm{N}}{400} \mathrm{CH}_{2} \mathrm{COOH}+\frac{\mathrm{M}}{40} \mathrm{CaCl}_{2}$ all desd
(7) $0.55 \mathrm{~m} \mathrm{NaCl}+\frac{\mathrm{N}}{600} \mathrm{CH}_{3} \mathrm{COOH}$. all dead
(8) $0.55 \mathrm{~m} \mathrm{NaCl}+\frac{N}{600} \mathrm{CH}_{3} \mathrm{COOH}+\frac{\mathrm{M}}{40} \mathrm{CaCl}_{2}$ all dead
(9) $0.55 \mathrm{~m} \mathrm{NaCl}+\frac{\mathrm{N}}{800} \mathrm{CH}_{2} \mathrm{COOH}$. all dead
(10) $0.55 \mathrm{~m} \mathrm{NaCl}+\frac{\mathrm{N}}{800} \mathrm{CH}_{3} \mathrm{COOH}+\frac{\mathrm{M}}{40} \mathrm{CaCl}_{2}$ all dead

Thus $\mathrm{CaCl}_{2}$ in concentrations which completely prevent the toxic action of the $\mathrm{NaCl}$ solution has no effect on the toxic action of acetic acid. $\mathrm{CaCl}_{2}$ also showed no antitoxic action in $0.55 \mathrm{~m} \mathrm{NaCl}$ containing $\mathrm{NH}_{4} \mathrm{OH}$ in concentrations from $\frac{N}{40}$ to $\frac{N}{256}$. It also failed to antagonize $\mathrm{HCl}$ in concentrations from $\frac{N}{800}$ to $\frac{N}{3200}$; but with weaker solutions $\left(\frac{N}{6400}\right.$ to $\left.\frac{N}{25^{5} 00} \mathrm{HCl}\right)$ some antitoxic effect was seen. Arbacia eggs thus differ from Fundulus eggs, which are protected by salts to a considerable degree against injury by acetic acid in $\frac{N}{3} \frac{N}{3}$ concentration (cf. J. Loeb, Biochemische Zeitschrift, 1912, vol. 47, p. 151). Fundulus eggs are, however, surrounded by a resistant chorionic membrane. 


\section{CONCLUSIONS}

We reach thus the general result that the formation of fertilization-membranes and the initiation of cleavage may be prevented by anesthetics when the parthenogenetic agent is a neutral salt, but not when it is a fatty acid. This contrast is what would be expected on the assumption that the essential action of the anesthetic is superficial, and consists in rendering the plasmamembrane more resistant to alterations of permeability. Hence the salt, which does not readily penetrate the unaltered egg and produces its effect by increasing the permeability of the plasmamembrane, is rendered less effective when the membrane has been rendered relatively resistant or stabilized by the anesthetic. The fatty acid, on the other hand, which penetrates the plasmamembrane readily under all conditions, by virtue of its lipoidsolubility, is not prevented in its action by anesthetics.

Fatty acids and neutral salts represent two classes of agents, one of which penetrates the egg-surface readily, the other with difficulty and apparently only after increasing the permeability of the plasma-membrane. Both induce parthenogenesis in a typical manner. It is significant that of these two parthenogenetic agents one should be influenced in its action by anesthetics, the other not. The fact that it is the more penetrating of the two which is uninfluenced seems to indicate that the agent produces its essential effect by acting on some portion of the eggcytoplasm situated within the most external surface-layer, and that calcium and anesthetics inhibit the action of salt-solutions because they prevent the access of the salt to this critical region of the egg. Otherwise it is difficult to understand why the anesthetic, which apparently stabilizes the surface-layer and hinders alteration of permeability, is without influence on the action of the fatty acid, although it inhibits the action of the salt. The entrance of the salt but not of the lipoid-soluble fatty acid would be hindered by agents which act (like anesthetics and Ca salts) by preserving semi-permeability unaltered, since semi-permeability relates to lipoid-insoluble substances ${ }^{18}$ only, as Overton first showed.

18 I.e., non-colloidal substances. Ruhland has shown that various dyes which form colloidal solutions are exceptions to Overton's general rule. Cf. Jahrb. wiss. Botanik, 1908, Bd. 46, p. 1. 
It is of course also possible that the actual entrance of the salt into the egg is unnecessary, and that a purely superficial action sufficient to increase permeability to a critical degree and thus cause a definite depolarization-effect is all that is necessary. There is at present no certain means of deciding between these two alternatives. If the salt increases permeability to a sufficient degree, it will naturally enter the egg and produce certain effects in its interior. It is, however, clear that there is nothing specific about the salt-action; all that is needed is that it should be sufficiently energetic. The entrance of special substances from outside into the egg is not necessary for parthengenesis: the effects of temporary warming and mechanical agitation upon starfish eggs are a sufficient proof of this. On the other hand, certain substances as fatty acids and lipoid-soluble alkalis, do undoubtedly produce their effects by penetrating the egg. ${ }^{19}$ The comparative ineffectiveness of the lipoid-insoluble and nonpenetrating alkalis and acids indicates this clearly. The most probable conclusion seems to be that the same effect can be produced by a purely superficial action, like that of a salt or the electric current, as by one operating at some region within the interior of the egg.

There are many indications that the primary effect in the activation of the egg-whether by the spermatozoön or a parthenogenetic agent-is superficial and consists in an alteration of the surface-layer of protoplasm-the region somewhat vaguely designated as plasma-membrane. The term 'plasma-membrane' in its application to the surface-film seems at present to require more precise definition. The conception of this structure as a thin homogeneous haptogen membrane exercising passive mechanical and osmotic functions is clearly inadequate. It must rather be regarded as essentially a superficial portion of the living protoplasm, characteristically modified in its composition and physical properties by surface forces. We must thus ascribe to it a characteristic chemical organization and metabolism as well as the characteristic physical and other properties, such as

${ }^{19} \mathrm{Cf}$. Loeb's recent paper on "The comparative efficiency of weak and strong bases in artificial parthenogenesis," Jour. Exp. Zoöl., 1912, vol. 13, p. 577. 
selective semi-permeability, that have led to its distinction from the more internal protoplasm. Conceived in this way, it corresponds closely to what morphologists designate as the cortical region of the egg, or at least to the most external layer of this region.

Changes in this region form a highly characteristic accompaniment of fertilization in many if not in all eggs; associated with these changes is a marked temporary increase in the general permeability of the surface-layer. The relation of these surfacechanges or cortical processes to the initiation of cell division and development is evidently a critical one. ${ }^{20}$ Once they are accomplished the developmental mechanism, hitherto held in check, resumes operation and-provided external and other conditions are favorable-continues its course automatically to the adult stage. It is clear, from the diversity of the conditions that may initiate development, that some process specific to the egg and quite independent of the nature of the activating condition forms the primary event in fertilization. The spermatozoön or the parthenogenetic agent in some way removes the hindrance to this process. What the nature of the latter is may be partly inferred from the results of recent experiments on the physiology of fertilization. The observations described in this paper support the view that some change in the cortical region of the egg-protoplasm, beneath the most external semipermeable layer of plasma-membrane proper, forms the initial stage of the fertilization-process. The immediate surface of the egg has semi-permeable properties relatively to most watersoluble lipoid-insoluble substances, and apparently must undergo increase of permeability in order that such a salt as $\mathrm{NaI}$ or KCNS may produce its characteristic effect. As already said, it is uncertain whether the salt acts by entering and then affecting directly the state of the colloids in the cortical region, or whether it acts without entrance, possibly by altering the electrical polarization of the plasma-membrane. It seems probable, however, from the general effectiveness of lipoid-alterants, that some

${ }^{20}$ Cf. F. R. Lillie, on The cortical changes in the egg of Nereis. Jour. Morph., 1911, vol. 22, p. 361. 
change in the condition of the lipoids-possibly in the interrelations between lipoids and proteins-is the primary effect produced and that this change then initiates some specific chemical reaction which determines directly or indirectly the characteristic surface-changes of fertilization, namely, secretion of cortical material, formation of fertilization-membrane, temporary change in osmotic properties of the plasma-membrane with accompanying electrical depolarization.

This view emphasizes the analogy between the activation of the resting egg and the general process of stimulation. ${ }^{21}$ In stimulation the primary event is a depolarization of the limiting membrane; similarly in the fertilization-process the electrical variation accompanying the above surface changes forms most probably the critical or 'releasing' event on which the rest of the process automatically follows. One gains the impression that in the resting egg-cell, as well as in the resting muscle or nerve, certain substances are hindered from interacting by the electrical polarization at the cell-surface; just as in a battery with open circuit the chemical reactions on which its operation depends are held in check by the polarization at the surface of the plates: ${ }^{22}$ that is, the passage of ions into or out of solution is thus prevented and with it all effects, chemical and other, dependent on the flow of electricity through the circuit. Under analogous conditions in the living cell a brief depolarization might suffice to release the impediment to the chemical interaction forming the primary event in the response--whether to stimulation or (in the case of the egg-cell) to fertilization. It is noteworthy that in many if not in most irritable cells the response is specific and constant and independent of the character and intensity of the stimulus; that is, recent research indicates that the "all or none" law applies to irritable elements in general, ${ }^{23}$ and not only to heart-muscle, and it may be said

${ }^{21}$ For a fuller discussion of this analogy, cf. my recent paper in the Journal of Exp. Zoöl., 1913, vol. 15, p. 23.

${ }_{22}$ The solution-tension of the ions being compensated by the electrostatic attraction between the plate and the oppositely charged adjoining layer of solution.

${ }^{23}$ Cf. especially the recent articles from the Cambridge Physiological Laboratory by Lucas and Adrian in the Journal of Physiology. 
with some qualification to apply also to the resting egg-cell. The removal of an inhibiting condition, whatever the means employed, is the essential requirement for fertilization. What follows is determined entirely by the nature of the egg itself.

The recent work of F. R. Lillie ${ }^{24}$ reinforces still further this general point of view. His results indicate that in fertilization a union of a specific amboceptor-like substance, contained in the egg-cortex, with some other specific substance, also furnished by the egg, forms the primary or determinative event. The spermatozoön acts by removing the hindrance to this interaction, but other agents may act similarly-hence the possibility of parthenogenetic fertilization. This conception makes it clear why the presence of the sperm is unnecessary to the activation of the egg, and suggests that in its activating capacity this structure plays essentially the part of a specific releasing mechanism, in a manner which is thus closely analogous to that of a stimulus, as already indicated. The ensuing developmental processes are specific to the egg under investigation and require special analysis in each case.

\section{SUMMARY}

The chief experimental results and general conclusions of this paper may be briefly summarized as follows:

1. The action of pure isotonic solutions of neutral salts $(0.55$ $m$ KCNS, NaI) in inducing formation of fertilization-membranes and cleavage in the unfertilized eggs of Arbacia may be prevented by anesthetics as well as by calcium and magnesium salts. The effective concentrations are those which just suffice to prevent cleavage in fertilized eggs.

2. The anesthetics are less effective than calcium or magnesium, and vary characteristically in effectiveness. The monohydric alcohols of the aliphatic series are the most favorable of those tried; the order of relative favorability runs: i-amyl $>n-$ butyl > n-propyl and capryl > ethyl. Phenyl and ethyl urethanes have comparatively slight action, and chloral hydrate still less. Cyanide is ineffective.

${ }^{24}$ Cf. Science, N. S., 1913, vol. 38, p. 524. 
3. The anesthetics have no inhibiting influence on the cleavage-initiating action of fatty acids. Since fatty acids readily penetrate the unaltered plasma-membrane, while salts do not, and since both agents are equally effective in inducing parthenogenesis, this difference indicates that the parthenogenetic agent acts at some point within the most external layer of the egg.

4. The favorable effects of after-treatment with hypertonic sea-water are prevented by anaesthetics as well as by cyanide. This result indicates that hypertonic sea-water, as well as anesthetics, acts by modifying the condition of the plasma-membrane. 